\title{
El pueblo mártir hoy y la esperanza que nos trae
}

\author{
Martha Zechmeister, \\ Departamento de Teología, \\ San Salvador.
}

\section{Introducción}

Monseñor Romero, al igual que Rutilio Grande, su precursor, e Ignacio Ellacuría, su seguidor y eco reflexivo, tenían, en su momento histórico, en los años antes y durante la guerra civil salvadoreña, el carisma profético y la genialidad de dar voz al sufrimiento del pueblo. Un pueblo sacrificado en este momento al ídolo de la riqueza, macheteado en su lucha justa por una vida digna, expuesto a la violencia despiadada y bárbara, expulsado de su hogar y su tierra, viviendo la pesadilla de las torturas, de las guindas y de la separación de sus seres queridos. Este mismo pueblo entendía de una manera espontánea e inequívoca: Rutilio, Monseñor Romero y Ellacuría hablan de nosotros, de la realidad que sufrimos día a día en nuestra carne. Nosotros somos el "pueblo crucificado", nosotros somos "el pueblo mártir". Y no solamente hablan de nosotros, sino que nos dignifican y nos entregan una esperanza última: ¡Ustedes son el cuerpo del Cristo crucificado en la historia! Ustedes son la carne martirizada -así como la carne del pobre hombre de Nazaret, en el que Dios se hace presente en este mundo configurado por el pecado.

Con Rutilio Grande, Monseñor Romero e Ignacio Ellacuría, irrumpió un nuevo modo de anunciar el evangelio y de denunciar el pecado en la Iglesia salvadoreña. Este nuevo modo de hablar rechaza rotundamente el "docetismo" teológico y pastoral, la palabrería sin carne y vacía de realidad. En este nuevo lenguaje se encarna "la palabra viva y eficaz de Dios, y más cortante que espada de dos filos" (Hb 4, 12). Esa palabra crea realidad, es "liberadora y salvadora, como el lenguaje del mismo Jesús"'.

1 D. Bonhoeffer, "Reflexiones para el bautizo de D. W. R. Bethge", en Resistencia y sumisión. Cartas y apuntes desde el cautiverio (Salamanca, 2008, p. 161). 
Rutilio Grande, Monseñor Romero e Ignacio Ellacuría tenían un don genial para dar palabra a la realidad, al sufrimiento del pueblo. Pero no solo eso otorga a su lenguaje potencial salvador y esperanzador, un lenguaje que llega sin rodeos a los corazones de los más vulnerables, sino que también contribuye a ello la coherencia firme y total de su vida. Una coherencia que sellaron con su martirio y con su sangre.

Hacer memoria de los mártires y celebrarlos es peligroso. Nos obliga también a nosotros a dejarnos tocar en nuestras entrañas por la angustia, por el martirio que sufren las víctimas hoy. Nos obliga a arriesgar lo que parece una locura autodestructiva: lanzarnos con toda nuestra existencia contra la maquinaria que aplasta brutalmente a los vulnerables. Hacer memoria del cuerpo y de la sangre de los mártires, entre ellos el protomártir Jesús de Nazaret, no permite ninguna "celebración light". O nos inicia en su seguimiento o es pura mentira y lleva consigo su "propia condena" (cf. 1 Cor 11, 29).

Poner a producir el legado de los mártires, hacer teología fiel a su herencia, no permite ninguna repetición estéril, ni mecánica. Se puede ser especialista en el pensamiento de Ellacuría, conocerlo y analizarlo hasta la última letra, pero traicionarlo. Estudiar profundamente el pensamiento de los mártires es una tarea de suma importancia, que exige todo nuestro rigor intelectual. Pero nunca puede ser un fin en sí mismo, una tarea meramente académica. Ser fieles a su legado nos obliga a un ejercicio paciente de contemplación, de atención sincera a la realidad, que vive el pueblo crucificado hoy. Si lo hacemos de verdad, duele; duele hasta el "tuétano de los huesos". Sin embargo, solo de ese dolor puede nacer de nuevo una palabra teológica y pastoral eficaz y esperanzadora, fiel a la herencia de los mártires.

Como teólogos y teólogas de la UCA, estamos cansados de responder a la objeción que el pensamiento de los mártires ya ha perdido vigencia y pertenece a una época pasada, porque el "paradigma" ha cambiado. Ciertamente, estamos conscientes de que su creatividad nos prohíbe darle trato de museo. Al contrario, la creatividad de su pensamiento nos compromete para movilizar nuestra propia creatividad. En efecto, tenemos que "actualizar" la herencia de los mártires. Ahora bien, qué quiere decir "actualizar". Ignacio Ellacuría nos lo explica de manera concisa: "Actualizarlo no significa primariamente ponerlo al día, al menos en el sentido que esta expresión puede tener de estar a la moda de los tiempos. Actualizarlo significa, más bien, dar realidad actual..."'. Eso es lo que intentaré hacer a continuación, es decir, dar realidad actual a la herencia de los mártires.

2. I. Ellacuría, "Utopía y profetismo", en Mysterium iberationis. Conceptos fundamentales de la Teología de la liberación, I (San Salvador, 1990, p. 398). 


\section{1. "Ustedes son el Divino traspasado"}

El 19 de junio de 1979, en el pueblo golpeado de Aguilares, Monseñor Romero pronunció una de sus homilías más preciosas. Jon Sobrino nos ha recordado muchas veces que, en el preámbulo de esa homilía, Mons. Romero redefine su oficio episcopal de una manera trágica y acertada: "A mí me toca ir recogiendo atropellos y cadáveres..." al pueblo sufrido de Aguilares: "Ustedes son la imagen del Divino Traspasado [...] que presenta a Cristo clavado en la cruz y atravesado por la lanza. Es la imagen de todos los pueblos, que como Aguilares, serán atravesados, serán ultrajados..."'.

Monseñor Romero identifica, de manera audaz y valiente, la cruz de Jesucristo con el horror que vivía el pueblo de Aguilares, en ese momento, expuesto a la violencia, a la crueldad y a la humillación. Afirma la "unión hipostática" entre el pueblo crucificado y el Cristo crucificado, ambos son una sola carne y no se pueden separar. En consecuencia, el pueblo crucificado es la presencia de Dios y su obra salvífica en este mundo es el sacramento de nuestra salvación en la historia.

En esa declaración solemne, Monseñor Romero dirige nuestra atención a la inmensa mayoría de los seres humanos de nuestro planeta, que suelen ser invisibilizados por quienes se declaran a sí mismos los verdaderamente "relevantes". Ciertamente, en el "primer mundo" y en los condominios de los ricos de El Salvador también hay sufrimiento, se mueren niños de cáncer o jóvenes en accidentes trágicos. No hay ninguna existencia humana sin sufrimiento. Pero hay un sufrimiento desmesurado, propio del pueblo crucificado. Es el pueblo mártir por el mero hecho de vivir un sufrimiento exagerado e injusto. Su vida parece un viacrucis sin final, un calvario permanente.

De ahí que, en la actualidad, debemos arriesgarnos a hacer lo mismo que hizo Monseñor Romero en 1977. Afirmar frente al viacrucis actual del pueblo salvadoreño: "Ustedes son el Divino Traspasado". Me parece oportuno concretar, dar carne, a esa afirmación con la historia de una familia salvadoreña. Obviamente, solo refleja un reducido sector de una realidad mucho más compleja. Sin embargo, desgraciadamente, la historia de esta familia no es una historia singular, sino mucho más, es una historia ejemplar, porque relata la pesadilla vivida en la actualidad por alrededor de un tercio de los salvadoreños todos los días, en colonias como Popotlán (Apopa), La Campanera o Las Margaritas (Soyapango), y en Lourdes, Panchimalco, el mero centro de San Salvador y en muchos lugares más.

3. Ó. A. Romero, "Homilía en Aguilares, el 19 de junio de 1977", en Homilías, tomo I (San Salvador, 2005, p. 149).

4. Ibid., p. 150. 
Todos los años, el domingo de ramos y el viernes santo, escuchamos el relato de la pasión. Obviamente, para la primera comunidad fue de suma importancia prestar atención a cada detalle de esa serie de hechos trágicos, ocurridos en los últimos días de Jesús. La fórmula introductoria de la liturgia reza de la siguiente manera: "Pasión de nuestro Señor Jesucristo". Así, nos invita a acompañar a Jesús con un corazón abierto y compasivo. Si Monseñor Romero tiene razón, de lo cual estoy convencida, al exclamar " UUstedes son el Cristo traspasado!", entonces, conviene contemplar la historia de esta familia con la misma atención contemplativa para acompañar a sus integrantes en todo lo que le pasa, de la misma manera que acompañamos a nuestro Señor Jesucristo en $s u$ viacrucis.

Voy a tratar de hacerlo a la manera de Marcos, esto es, contar los hechos de la manera más sencilla y sobria. Pese a ello, parece poco creíble que en la vida de una sola familia se pueda acumular tanto. Es tan inverosímil como la historia de Job en la Biblia, sobre quien se descargan todas las desgracias imaginables. A diferencia de Marcos, no puedo proporcionar los verdaderos nombres, ni los lugares, por discreción y por el peligro que correría esta familia de hacerlo públicos.

\section{Relato de la pasión de una familia salvadoreña}

\section{Primer capítulo: desaparición y muerte violenta de Pablo}

Soy amiga de la madre de esta familia desde hace cinco años. En 2010, ella trabajaba como cocinera en el pupilaje donde vivía. De aquí en adelante la llamaré María, como símbolo de todas las mujeres con el corazón atravesado por una espada (Lc 2,35). Un día, observé que María, antes tan alegre, de repente se había puesto mal. Todavía no nos conocíamos bastante como para platicar en confianza sobre lo que le ocurría. Me dolió mucho que los responsables del pupilaje la despidieran sin vacilar en el instante en que decayó, física y psíquicamente.

Meses después, supe qué le había sucedido, cuando me buscó para pedir trabajo. Había desaparecido el segundo de sus tres hijos, de 17 años, que trabajaba como motorista de una panadería. Lo llamaré Pablo. Su empleador le había dado permiso para trasladarse al cantón donde vivía en el vehículo de la empresa. Un hecho que llamó la atención de los mareros. Estos le pidieron 60 dólares de renta. Como no los tenía, le dieron un plazo. Cuando este terminó, los mareros se llevaron al joven. Su madre, sus hermanos y sus primos lo buscaron desesperados. Después de tres meses de angustia, incertidumbre y el presentimiento del horror, encontraron el cadáver de Pablo, ya descompuesto, al lado de una milpa. Lo identificaron por su ropa.

En esos días, María estuvo al borde de una psicosis. Veía a su hijo por todos lados y hablaba con él. Sin embargo, se levantaba de nuevo para luchar por la vida, por la suya y por la de sus otros dos hijos. Desde entonces, ella trabaja con nosotros y prepara tres veces a la semana la comida de nuestra pequeña comu- 
nidad de diez personas. Es una cocinera creativa, con mucha chispa, siempre interesada en probar nuevas recetas.

\section{Segundo capítulo: expulsan a la familia de su hogar}

Cuando María apenas se había recuperado del primer dolor y había retornado a su rutina diaria, los mareros comenzaron a molestar de nuevo. Enviaron a niños de 8 y 9 años con papelitos, ornamentados con las peores palabrotas, para reclamar la "deuda abierta" o exigir la vida de otro miembro de la familia. Subieron la cuota a 500 dólares. No había otra alternativa que huir de inmediato a otro municipio lejano. Lograron conseguir una pequeña casa, bastante destruida, pero la arreglaron. Se entusiasmaron con la siembra de la semilla regalada por el gobierno para cultivar un poco de maíz y frijol. En ese momento, cuando brotaron las primeras plantas tiernas de esperanza y se sentían seguros, María se animó a denunciar al asesino de su hijo, el cabecilla de la mara local, donde habían vivido antes. La policía le prometió el estatuto de testigo protegido. Pero la fiscalía promovió un careo entre ella y el marero, separados solo por un vidrio. María no confió en que el vidrio fuera blindado y sospechaba que la habían expuesto al asesino de su hijo. Desde entonces, vivía presa del miedo por las consecuencias.

\section{Tercer capítulo: violan a María y sigue la guinda de la familia}

Sus peores temores se cumplieron con el siguiente golpe. En la navidad de 2011, María, contenta, porque había cobrado su aguinaldo, se dirigió a su casa con las compras para la cena festiva - pollo, verdura y frutas. En el camino solitario que conducía a su vivienda, cinco hombres encapuchados la asaltaron y la violaron. La pena le impidió decir nada a sus hijos. Pero insistía en que era necesario huir de nuevo y lo más pronto posible. Los hijos no entendían nada y de mala gana abandonaron su casa y se trasladaron con ella a los suburbios de San Salvador. Desde el principio les quedó claro que se habían metido de nuevo en una cueva de mareros, pero solo sitios como ese estaban al alcance de sus ingresos. Ya habían perdido mucho de lo poco que tenían en los dos traslados anteriores.

María es, en mi opinión, la encarnación de la santidad primordial de la que habla Jon Sobrino. Lo sucedido hasta ahora basta para acabar con una persona. En su infancia había sufrido violencia y abuso. Ahora, el trauma de la violación múltiple y brutal le ocasionaba trastornos ginecológicos serios y una depresión profunda, manifiesta en apatía y lagunas mentales temporales. Maravillosamente, María reúne fuerzas y reasume su lucha. Ahora, para buscar ayuda médica y psicológica.

\section{Cuarto capítulo: atropellan a Pedro}

María recupera de nuevo con gran energía cierta normalidad cotidiana para ella y sus dos hijos. El mayor, al que llamaré Pedro, abandonó los estudios cuando desapareció su hermano, pocos meses antes de su bachillerato. Desde entonces, 
trabaja en un taller mecánico sin seguro ni otros derechos laborales. Cuando los reclamó, la respuesta de su empleador fue: "Sabés por qué puerta entraste, por la misma podés salir". Sin alternativas para encontrar otro empleo por carecer del bachillerato, Pedro se sometía. Su tarea consistía en buscar repuestos chatarra con su moto, en el área urbana. En marzo de 2013, en medio de la misa por Monseñor Romero, aquí en la UCA, me cayó una llamada en mi móvil. La corté pero, ante la insistencia, me salí de la capilla para aceptar la llamada. Lo primero que escuché eran los sollozos desesperados de María: "Se me muere mi hijo, se me muere mi hijo".

Pedro había sido atropellado con su moto en un semáforo por una ambulancia. Las llantas del vehículo pesado pasaron sobre su vientre. Parece una broma de mal gusto, pero los socorristas, en vez de atenderlo, huyeron para evitar las consecuencias del accidente. Medio muerto lo llevaron al Hospital Rosales. Pedro pasó varias horas dramáticas en el quirófano. La lucha por su vida se prolongó al menos quince días. Cabe mencionar que el médico que lo atendió es profesional y humanamente excelente. Pero solo quien conoce las condiciones de ese hospital puede imaginarse lo que significa para una madre acompañar a su hijo mientras lucha contra la muerte. María dormía unas pocas horas en el suelo, debajo de su cama.

\section{Quinto capítulo: insuficiencia renal grave de Chus}

Justamente cuando Pedro se recuperó y pudo retornar a su trabajo, aunque con dificultades, el más joven de los hijos comenzó a sentir molestias. Lo llamaré Jesús, Chus. En ese momento, Chus estudiaba el primer año de bachillerato en un colegio. La inestabilidad familiar le había hecho perder algunos años y ya era demasiado mayor para asistir a un instituto nacional. Por eso, su madre y su hermano hicieron un gran sacrificio para matricularlo en ese colegio. La cuota era modesta, pero representaba una fortuna para ellos. En diciembre de 2013, los médicos diagnosticaron la causa de su malestar: insuficiencia renal avanzada. Chus pasó varios meses en diálisis hasta que, en marzo de 2014, un tío por parte de su papá, ya difunto, le donó un riñón.

La tragedia ocurrió cuando Chus se recuperó: su tío murió de una infección en la herida. Él se bañaba muy temprano en el río contaminado que pasaba cerca de su casa. Entonces, Chus experimentó problemas psicológicos, causados por un enorme sentimiento de culpabilidad, pues vivía a costa de otro. Esos problemas agravaron la depresión típica del paciente que ha recibido un trasplante.

María continuó su heroica lucha. Llevaba a su hijo al tratamiento médico y psicológico, mientras rebuscaba apoyo en todas partes para adquirir los medicamentos y la leche especial que Chus necesitaba. 


\section{Sexto capítulo: sigue la persecución por las maras}

El acoso de los pandilleros se sumó a esos desastres. Querían obligar a Pedro, el hijo mayor, a hacer viajes para ellos en su moto, su herramienta de trabajo. Pudo evitarlo pagando una renta de veinticinco dólares mensuales, una cantidad superior a la décima parte de su salario. Y por si fuera poco, los mareros llegaban a la casa de la familia todos los domingos y exigían comida para quince de ellos. Cuando María solo tenía arroz y frijoles, se encolerizaron y reclamaron "comida de verdad".

Nuevamente, la única alternativa era continuar la guinda. Esta vez a un cantón rural, alejado de la capital. Tendrían un breve respiro, pero no por mucho tiempo, porque ahí no había cómo ganarse la vida. Diariamente, tenían que viajar cuatro o cinco horas para llegar al sitio de trabajo. El gasto en pasaje era demasiado alto. Pocos meses después, aceptaron su derrota y regresaron a los suburbios de San Salvador. Un sitio distinto, pero no por eso menos peligroso que el anterior. Los problemas se presentaron en seguida.

Los mareros capturaron a Chus en la entrada del colegio y lo golpearon fuertemente cuando aún la cicatriz de la cirugía estaba tierna. El mensaje fue claro. Lo matarían si aparecía cerca del colegio. María, que solo había estudiado dos grados de primaria, fue al Ministerio de Educación a luchar por su hijo. Pedía una posibilidad para que pudiera completar las pocas semanas que le faltaban para bachillerarse. En la lucha, a veces podía parecer exagerada o agresiva. Pero yo no lo veo así. Más bien, experimento algo de la "ira santa" de los profetas ante esa "agresión”. ¡Así no podía ser! Es pasión y fervor que reclama la vida. Por fin, los lamentos de la "viuda fastidiosa" (Lc 8, 4) conmovieron al director del colegio, que escondió a Chus en su propia casa. Además, lo ayudó a estudiar, según las guías del ministerio, y a prepararse para los exámenes.

Mientras Chus vivía en la casa del director, el resto de la familia permanecía expuesta a los caprichos de los mareros. Da la casualidad que el techo de la estrecha casita donde vivían era más bajo que el de las casas vecinas. Cuando la policía cateaba por las noches en busca de mareros, estos saltaban al techo bajo de la casita y se escondían en el patio de la familia. Esos sustos petrificaron a Pedro y María, a quienes no les quedó otra salida que el éxodo. Esta vez, junto con una buena cantidad de otras familias desesperadas.

Se refugiaron en un pueblo de los alrededores de la capital, cerca de sus parientes. Sabían que se metían en un territorio controlado por la mara contraria, enemiga mortal de la mara que los había torturado hasta entonces. Sabían que ese hecho los hacía sospechosos desde el comienzo. En diciembre de 2014, Chus obtuvo el título de bachiller. En ese momento, por casualidad, unos parientes que se habían ido mojados a Estados Unidos hacía ya muchos años, pasaron por el pueblo. Organizaron un almuerzo familiar para celebrar la graduación de Chus. 
Pusieron globos y una pancarta en la entrada de la casa que decía: "Felicidades en tu día de graduación". Eso llamó la atención de los mareros, que de nuevo se llevaron a Chus, los golpearon, porque "les caía mal", y le dijeron que lo "borrarían del mapa" o uno de sus parientes pagaría con su vida si no se unía a ellos o desaparecía inmediatamente del pueblo.

\section{Séptimo capítulo: el calvario de Chus}

Esa misma noche, un tío llevó a Chus en su pick-up a la casa de un amigo, en una colonia de San Salvador, cerca del restaurante chino, donde lavaba platos por un salario muy bajo. Pero los mareros lograron encontrarlo y le dispararon en pleno día. Logró escapar de milagro. Muerto de nervios, corrió a donde unos parientes colaterales, que vivían muy lejos en el campo.

Ahí, Chus ayudaba en la cría de ganado. La mujer de la casa lo trataba muy bien. Pero los jóvenes, acostumbrados al trabajo duro del campo, se burlaban de él por ser muy flaco y tener problemas de salud. Cuando se dieron cuenta de que tenía un riñón trasplantado, le dijeron: "Tu vida ya no vale nada, estás como un trapo viejo". De repente, recibí otra llamada de María, totalmente desesperada: "Se me muere mi hijo, se me muere mi hijo". La llamada cayó tarde en una noche de enero de 2015. Chus había llegado más allá del límite de sus fuerzas y había intentado acabar con su vida. Se había tomado una pastilla de sulfuro, usada como pesticida, junto con otras pastillas, que había encontrado en la casa. Los encontraron con convulsiones fuertes y echando espumarajos por la boca. Lo llevaron al hospital, donde le lavaron el estómago y lo rescataron en el último momento. Sobrevivió con los intestinos quemados y una depresión profunda.

María y Pedro buscaron de nuevo una salida bajo una presión increíble. En el pueblo donde vivían, la pandilla había hecho la situación insoportable. Los vecinos, incluidos sus parientes, que habían vivido ahí durante varias generaciones, ya lo habían abandonado. De repente, María y Pedro se encontraron en medio de casas abandonadas. Asimismo, pensaron que no podían dejar solo a Chus por miedo a que repitiera el intento de suicidio. Pensaron irse mojados al Norte, en buscar una visa humanitaria o irse al sur centroamericano. De momento, gracias a Dios, pueden respirar un poco más tranquilos. Encontraron gente buena que los protege en El Salvador y se ocupa del tratamiento médico de Chus.

\section{El pueblo mártir carga y denuncia el pecado del mundo}

El relato de la pasión de esta familia salvadoreña representa lo que muchos sufren de igual o peor manera. Escuchándolo, se imponen las estaciones del viacrucis, tal como lo rezamos tradicionalmente: cuántas caídas bajo el peso de la cruz y cuánta energía para levantarse y seguir de nuevo en el camino. Y en la tragedia, Simón de Cirene: el médico del Hospital Rosales, que ayuda a Chus con 
su cruz; el director del colegio, que con dudas lo esconde en su casa, y, por fin, el tío, que salva su vida y en el intento pierde la suya propia.

La sola existencia del pueblo crucificado, del pueblo mártir, es una denuncia profética, que grita a voces el "pecado del mundo", acusa a las fuerzas y a los poderes que causan su crucifixión diaria. Aguantemos un poco más la contemplación de esa pasión y tratemos de descifrar la denuncia. La historia de la familia de María podría ser el punto de partida de un estudio socioeconómico y político de los males que flagelan a una porción considerable de los salvadoreños. Aquí, solamente puedo señalar algunos aspectos.

\section{a. La pérdida de la identidad}

Las homilías de Monseñor Romero terminaban todos los domingos con una denuncia de la violencia que sufría el pueblo, las desapariciones, las torturas, las masacres. Meticulosamente investigadas por su equipo, Monseñor proporcionaba fechas, lugares, nombres y apellidos de las víctimas y de los verdugos. Sacar las atrocidades de la clandestinidad a la luz pública daba protección a las víctimas, al menos protección contra la difamación de ser mentirosas. Monseñor Romero hizo visibles los rostros de las víctimas y así les devolvió su dignidad.

Hoy en día, la ley que aparentemente rige a El Salvador con mano dura es la leyenda que se puede leer en los grafitis de tantos pasajes de las zonas de alta peligrosidad: "Ver, oír, callar". Al contar la historia de mis amigos, siento una fuerte frustración, por tener que ocultar su identidad. No puedo, por ejemplo, mostrar una preciosa foto de la madre orgullosa junto a su hijo, en el momento de su graduación como bachiller. Todos los que viven en una situación como la de ellos ya han padecido la muerte social múltiple. No pueden confiar en sus más cercanos, tienen que desaparecer de golpe, sin despedirse de nadie. El famoso tejido social, roto con los desplazamientos provocados por la guerra, en vez de recuperarse, se descompone cada día más. A personas como María, apenas han echado raíces, siempre se las cortan de nuevo, huyen en guinda permanente, acosadas y perseguidas.

\section{b. Los "efectos secundarios" de la pobreza y la vulnerabilidad}

Personas como María, expuestas a un estrés permanente, sufren daños físicos y psíquicos serios. Una vida bajo continua ansiedad y tensión alta provoca toda clase de enfermedades psicosomáticas: colitis, úlcera, migraña y otras muchas dolencias, típicas de los pobres. Si para una persona sana y robusta ya es difícil conseguir un empleo decente y estable, para una persona con múltiples traumas, es casi imposible. El círculo se cierra con la lucha constante para obtener acceso a terapias y medicamentos adecuados. Están forzadas a mendigar indignamente algo que les pertenece por la Constitución: el derecho a la salud. 


\section{c. La impunidad escandalosa y el pueblo desprotegido}

La impunidad escandalosa parece abatirse sobre El Salvador como una maldición tremenda. A partir de la "amnistía general" para los verdugos de la guerra civil, los crímenes capitales nunca castigados se multiplicaron progresivamente. Los asesinos parecen intocables. Los vulnerables no tienen refugio, no tienen a nadie a quien recurrir, ninguna instancia les ofrece protección eficaz. La policía y la justicia, además de estar infiltradas, cuando hacen el esfuerzo de colocarse del lado de las víctimas, parecen desvalidas. Sus cateos y detenciones, dramáticas muchas veces, parecen un gran show mediático, que encubre su verdadera impotencia y representa una amenaza más para el pueblo flagelado.

Gracias a Dios, hay agentes policiales y funcionarios de la justicia honrados. Asimismo, hay instituciones como el Instituto de Derechos Humanos de la UCA (Idhuca) y muchas otras de buena voluntad. Pero todo esto parece más bien una gota en el océano. Por lo general, el pueblo mártir está abandonado, tal como dice el salmista: "Me he quedado sin refugio, nadie se ocupa de mí [...] Atiende a mi clamor, pues estoy del todo agotado; líbrame de mis perseguidores, que son más fuertes que yo" (Sal 142, 5.7).

\section{d. La múltiple victimización}

Jóvenes como Chus, el protagonista de nuestro relato, siempre están bajo sospecha. La primera reacción del que se entera de alguien que ha huido para salvar su vida es: "Por algo será", "En algo anda metido". La víctima siempre carga con la imputación de que los horrores vividos son culpa suya. Este diagnóstico puede ser el mantra del mismo pueblo vulnerable: "A mí no me va a pasar eso, porque yo no ando metido en nada". Pero ese mantra es engañoso y satánico, porque desolidariza. Peor todavía si ese diagnóstico proviene de quienes viven cómoda y seguramente, y justifican su apatía y la dureza de sus corazones con la desvergonzada afirmación que sentencia: "Lo que les pasa, se lo tienen merecido".

Victimizar a las víctimas una y otra vez es intolerable. Incluso los mismos mareros, muchas veces son a la vez victimarios y víctimas. Y ellos también son seres humanos. Por eso, también es intolerable la demanda vulgar que reclama "fumigar a las cucarachas". Hay que exigir justicia, pero no un trato deshumanizante, que no permite la resocialización y que los convierte en estas bestias, que una parte desalmada de la sociedad proyecta en ellos.

\section{e. "El pecado del mundo"}

La pasión del pueblo mártir salvadoreño grita a voces el pecado del microcosmo de este país. En realidad, la situación es mucho más compleja de lo que puedan indicar estas pocas observaciones. No podemos tratar aquí a las maras con el simplismo que les atribuye, mitológicamente, ser "la fuente de 
todo el mal". Ciertamente, las pandillas sirven de camuflaje a fuerzas mucho más poderosas como el crimen organizado, la mafia de las drogas y del tráfico internacional de armas. No podemos comprender el pecado que el pueblo mártir denuncia sin contextualizarlo en el escandaloso desorden global.

Se imponen las fuertes palabras que Ignacio Ellacuría pronunció en el discurso de Barcelona, diez días antes de su asesinato: "Lo que en otra ocasión he llamado el análisis coprohistórico, es decir, el estudio de las heces de nuestra civilización, parece mostrar que esta civilización está gravemente enferma"5. Reformulado desde mi propia experiencia, siento que la realidad de El Salvador es como un "espejo cóncavo", donde se revela y se densifica la verdad de la totalidad de nuestro mundo. El sufrimiento actual del pueblo mártir, en las zonas de alta peligrosidad del país, proyecta la mueca repugnante del desastre y del desorden global, que privilegia de manera obscena a unos pocos, mientras martiriza al menos a un tercio de la humanidad. En octubre de 2014, Oxfam, una organización no gubernamental con prestigio internacional, denunció que las 85 personas, individuos, más ricos del mundo poseían los mismos recursos económicos que la mitad más pobre de la población mundial, 3,500 millones de personas. Según la proyección de Oxfam, dentro de poco, el uno por ciento más rico del mundo poseerá más que el otro 99 por ciento ${ }^{6}$.

Obviamente, la afirmación de Ellacuría, que denunció que el motor que mueve la historia es la codicia y la acumulación de capital, no ha perdido actualidad. En algunas regiones de esta tierra, la pobreza y sus consecuencias son mucho más mortíferas que en El Salvador. Pero en pocas regiones la escandalosa diferencia entre quienes viven en la abundancia y quienes están expuestos a la vulnerabilidad permanente se densifica tanto como en El Salvador.

Entre esos extremos, entre los autores y las víctimas del desorden económico, se encuentran los pequeños beneficiarios del sistema neocapitalista, personas como yo, como la mayoría en el "primer mundo" y como la clase media de El Salvador. Nos hacemos de la vista gorda. Somos poca cosa en comparación con los adinerados de verdad, pero vivimos bien, cómodos, en zona segura, y muchas veces nos mostramos desinteresados y espantosamente apáticos ante el pueblo que carga con la cruz.

En la tercera semana de los Ejercicios espirituales, Ignacio de Loyola pide al ejercitante "esforzarse por sentir dolores, estar triste y llorar". Hace pedir "dolor con el Cristo crucificado, lágrimas... por la tortura que Jesucristo sufrió por mí" (EE 195 y 203). La objeción psicologizante nos dice que esa es una fijación en lo

5. I. Ellacuría, "El desafío de las mayorías pobres", ECA (1989), 493-494.

6. Oxfam, "Iguales: acabemos con la desigualdad extrema", 29 de octubre de 2014. Disponible en https://www.oxfam.org/es/informes iguales-acabemos-con-ladesigualdad-extrema. 
negativo, que nos lleva al sadomasoquismo. Pero esa petición debemos leerla en la clave del otro gran Ignacio, Ignacio Ellacuría. Podemos entender los Ejercicios espirituales como una escuela de compasión, que desencadena en nosotros una dinámica completamente distinta al malentendido tradicional: dejarme conmover en mis entrañas por el sufrimiento que todos los días inflige el "pecado del mundo", nuestro pecado, a los Pablo, Pedro, Chus y María de nuestro planeta, y llorar por mi comodidad, por mi falta de coraje e iniciativa para detener su viacrucis sin fin. Es necesario actualizar, dar realidad actual de nuevo, a la llamada a la conversión de Ignacio Ellacuría, una llamada que podemos considerar como su testamento espiritual:

Lo único que quisiera [...] son dos cosas: que pusieran ustedes sus ojos y su corazón en esos pueblos que están sufriendo tanto - unos de miseria y hambre, otros de opresión y represión- y después (ya que soy jesuita), que ante ese pueblo crucificado hicieran el coloquio de san Ignacio en la primera semana de los Ejercicios, preguntándose: ¿qué he hecho yo para crucificarlo?, ¿qué hago para que lo descrucifiquen?, ¿qué debo hacer para que ese pueblo resucite??

\section{El pueblo mártir es el "sacramento de la salvación"}

Ignacio Ellacuría comienza su ensayo crucial sobre el pueblo crucificado $^{8}$ con una pregunta inquietante: ¿cómo es posible que una gran parte de la humanidad siga "literal e históricamente crucificada", cuando Jesús anunció el reino y la Iglesia ha proclamado nuestra salvación durante más de dos mil años? ¿El viacrucis sigue y sigue y sigue? ¿Qué quiere decir salvación frente al hecho de que "la mayoría de la humanidad oprimida" sigue cargando el pecado del mundo?

Ignacio Ellacuría nos cuestiona para sacarnos de la apatía y de la indiferencia y para sensibilizarnos ante el calvario del pueblo mártir. Nos saca de la "falsa espiritualización" de nuestro hablar sobre la salvación. Esa "dulcificación y mistificación" pervierte la salvación y la convierte en promesas vagas y vacías de realidad, igual que las promesas de las campañas electorales. Ellacuría nos pone en marcha para buscar y actuar la verificación de la salvación, en la historia aquí y ahora. A nuestra fe en la salvación le corresponde una realidad palpable, crea realidad, o es opio, que nos adormece y nos convierte en monstruos insensibles.

En este contexto inquietante, Ellacuría se pregunta: “QQuién es el pueblo elegido de Dios? ¿Quién es la verdadera Iglesia, el verdadero sujeto de la misión salvífica de Jesucristo en la historia?"9. El concilio Vaticano II nos dice que la

7. I. Ellacuría, "Las Iglesias latinoamericanas interpelan a la Iglesia de España", Sal Terrae, 3 (1982), 230.

8. I. Ellacuría, "El pueblo crucificado", en Mysterium liberationis, II, op. cit., pp. 189 y ss.

9. Ibid., p. 189. 
Iglesia es el "sacramento", el "signo e instrumento" de nuestra salvación. Para Ellacuría, esa afirmación es demasiado vaga. Hay que precisarla. Y la precisión es la inversión radical de la perspectiva. Pone patas arriba todas nuestras ideas. No se trata de cómo hablar de la salvación, a pesar de que la mayoría de la humanidad está golpeada y oprimida. Sino más bien al revés, debemos arrodillarnos ante el misterio: el pueblo mártir es el sujeto histórico de nuestra salvación. El pueblo mártir es el "sacramento", es decir, la presencia real y concreta de Dios en este mundo. El pueblo mártir es el instrumento primordial de la obra salvífica para toda la humanidad.

En sintonía con Jon Sobrino, es necesario afirmar que ¡la salvación viene de abajo! Y esa afirmación nos dice ante todo que la salvación no viene de arriba, ni de las cúpulas de los partidos, ni de las organizaciones no gubernamentales, que cuentan con recursos, ni de los programas internacionales de desarrollo. La inversión de la perspectiva, en total consonancia con el evangelio, resulta escandalosa.

Resulta escandaloso proponer a los necesitados y oprimidos como la salvación histórica del mundo. Resulta escandaloso a muchos creyentes, que ya no creen ver nada llamativo en el anuncio de que la muerte de Jesús trajo la vida al mundo, pero no pueden aceptar teóricamente, y menos aún prácticamente, que esa muerte que da vida pase hoy realmente por los oprimidos de la humanidad ${ }^{10}$.

La antífona del viernes santo reza: "En la cruz está la salvación, en la cruz está la vida, en la cruz está la esperanza". Cuando era joven, esa frase me provocaba una crisis. La cruz nos confronta con el pobre hombre Jesús de Nazaret, cruel e injustamente torturado hasta la muerte. ¿Cómo podemos afirmar que ahí están presentes la salvación, la vida y la esperanza? Ponernos de rodillas ante la cruz de Jesús, que nos trae salvación, es el mismo escándalo y la misma locura que ponernos de rodillas ante el pueblo crucificado y afirmar que él nos trae salvación. En eso consiste nuestra fe en Jesucristo, una fe encarnada, hecha carne en la humanidad torturada.

"No hay salvación fuera de los pobres", dice Jon Sobrino. Al concretar, al darle carne histórica a esa afirmación, en la actualidad, podemos decir que tampoco hay salvación fuera de las María, Pedro, Pablo y Chus de El Salvador y de todo el mundo. El amor creativo y redentor de Dios está presente en su lucha diaria y heroica por la vida. Con ellos, Dios pasa por este mundo. Ellos son los que cargan con nuestros pecados. Por sus heridas, somos salvados (Is 53). ¿Quién, si no ellos, puede arrancar nuestro corazón de piedra para darnos un corazón de carne? (Ez 36, 26). En ellos está presente la energía vital capaz de convertirnos y de humanizarnos.

10. Ibid., p. 192. 
El evangelio es una llamada fuerte a la conversión para el "mundo de arriba" -y es una gran promesa para los que sufren "abajo". A los últimos les dice: este "mundo" los considera como los desechos, los superfluos que no cuentan, como esos cuyas vidas "no valen nada". El "mundo del pecado", configurado por los poderes económicos, militares y políticos, o no hace nada para proteger sus vidas, o peor aún, se las arrebata activamente. Pero, en realidad, no hay solución ninguna para este mundo si no reconoce en ustedes y en la tortura que les hacen sufrir, el misterio de la cruz y de la resurrección de Jesucristo. No hay salvación para este mundo si no se inclina frente al misterio divino, presente en ustedes. 